\title{
Design of an LNG Tank for Accidental Loads in Finland
}

\section{Francisco MARTÍNEZ \\ Operations Manager \\ Principia \\ Madrid, Spain \\ francisco.martinez@principia.es}

Francisco Martínez, born 1963, received his $\mathrm{PhD}$ in civil engineering from the Madrid School of Civil Engineering. He has extensive experience in the design of LNG tanks, especially in relation with the effects of accidental loads.

\author{
Miguel Ángel ASTIZ \\ Project Manager \\ Carlos Fernández Casado. \\ Madrid, Spain \\ maastiz@cfcsl.com
}

Miguel A. Astiz, born 1950, was a graduate student at Stanford University and has a PhD from the Madrid School of Civil Engineering where he holds the Chair of Bridge Engineering. He has extensive experience in the design of bridges and pre-stressed structures such as LNG tanks..

\author{
Rafael FERNÁNDEZ \\ Director LNG Division \\ FCC Industrial \\ Madrid, Spain \\ RFernandez@fcc.es
}

\begin{abstract}
Rafael Fernández, born 1955, received his civil engineering degree from the Madrid School of Civil Engineering. He has 12 years of experience in LNG facilities and has been involved in the construction of 8 tanks.
\end{abstract}

\section{Summary}

The first tank in Finland for storage of liquefied natural gas (LNG) is currently being built in the port of Pori. It is a full containment tank, capable for $30,000 \mathrm{~m}^{3}$. Two of the many load cases considered in the design correspond to postulated accidents that give rise to complex thermalmechanical problems and are of especial interest in the Pori tank: the major leak event (in which the liquid at $-168^{\circ} \mathrm{C}$ contacts the concrete outer tank) and the external fire (with the tank being subjected to large thermal fluxes from a postulated fire). The paper describes the calculations conducted to verify that the design adopted satisfies the success criteria established for those events.

Keywords: liquefied natural gas tanks; major leak; fire; thermal-mechanical problems.

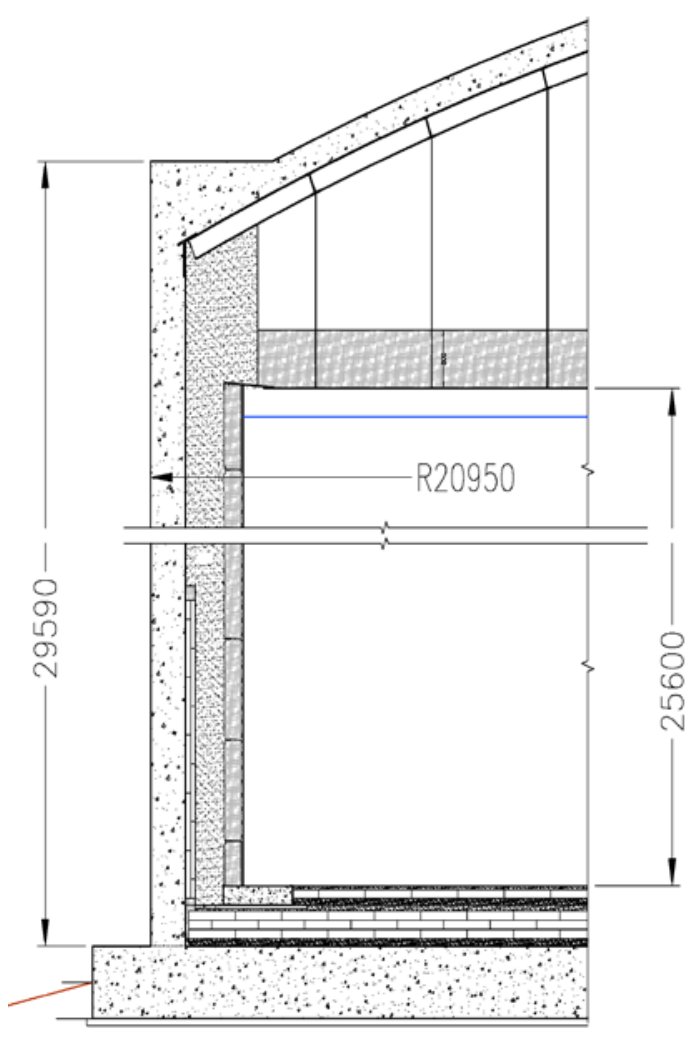

Fig. 1: Cross-section of the tank

\section{Introduction}

The first tank in Finland for storage of liquefied natural gas (LNG) is currently being built in the Tahkoluoto terminal in the port of Pori. The overall works include a storage tank where the liquid LNG is temporarily kept, facilities for transferring LNG to barges and lorries, and a vaporisation plant to return the liquid to gas form for distribution and use. The present paper is primarily concerned with the design of the storage tank from the structural point of view.

The tank has a storage capacity of $30,000 \mathrm{~m}^{3}$ and is of the full containment type, which indicates that it is designed to maintain impermeability to both liquid and gas at the operating temperature of $-168^{\circ} \mathrm{C}$. Tanks of this type are actually double tanks, composed of an outer tank and a self-supporting inner tank. The outer tank consists of a pre-stressed concrete cylindrical wall, capped by a reinforced concrete spherical dome and supported on a reinforced concrete slab. The inner tank is an open top cylindrical tank, made of cryogenic $9 \% \mathrm{Ni}$ steel in order to ensure good ductility at operating temperatures.

Traditionally, the connection of the wall and the base slab is protected by cryogenic steel and foamglass insulation up to an elevation of $5 \mathrm{~m}$, a detail known as the thermal corner protection (TCP). Also, perlite insulation is placed 
between the two tanks to minimise heat exchanges across the outer tank and the associated liquid boil-off. The base slab is heated to prevent the ground from freezing under the tank to avoid heave and volume changes in the ground, since the structure, especially the inner tank, is rather sensitive to differential settlements.

\section{Description of the tank and materials}

The Pori tank, a typical cross-section of which appears in Fig.1, is supported on 196 drilled steel piles filled with concrete. The wall of the outer tank has an internal radius of $20.35 \mathrm{~m}$ and a

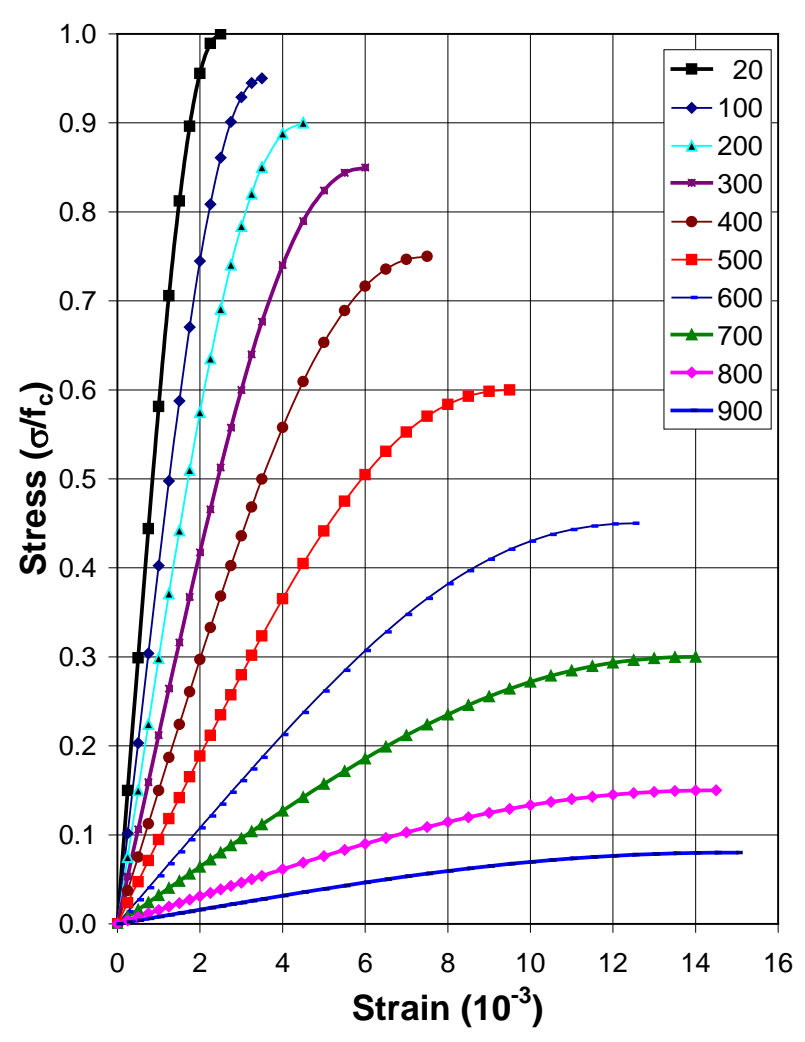

Fig. 2: Concrete uniaxial compressive behaviour thickness of $0.60 \mathrm{~m}$. The space left between the inner and outer tanks is $1 \mathrm{~m}$, the inner $0.30 \mathrm{~m}$ occupied by the resilient blanket and $0.70 \mathrm{~m}$ filled with perlite.

The external wall is built with C40/50 concrete. Its uniaxial compressive behaviour is shown in Fig. 2 for ambient and higher temperatures; the improvement in properties experienced for lower temperatures has been conservatively neglected. The temperature dependence of the thermal properties, such as specific heat, was also taken into account. The concrete was described with a continuum, plasticity-based, damage model. It assumes that the two main failure mechanisms are tensile cracking and compressive crushing. The evolution of the yield surface is controlled by two hardening variables linked to those two failure mechanisms.

Two types of steel are used: reinforcing KRYBAR-165 for locations with cryogenic requirements and B500 otherwise. The basic mechanical properties at $20^{\circ} \mathrm{C}$ of the reinforcing steel, the pre-stressing steel, and the concrete are summarised in Table 1.

A uniform arrangement of reinforcing bars,

Table 1: Mechanical properties at $20^{\circ} \mathrm{C}$

\begin{tabular}{lllll}
\hline Mechanical property & Concrete & Reinf. steel & Cryog. steel & Prestress. steel \\
\hline Young's modulus (GPa) & 35.0 & 200 & 200 & 200 \\
Poisson's ratio (-) & 0.2 & 0.3 & 0.3 & 0.3 \\
Yield stress (MPa) & - & 500 & 460 & 1,770 \\
Tensile strength (MPa) & - & - & - & 1,860 \\
Density $\left(\mathrm{kg} / \mathrm{m}^{3}\right)$ & 2,500 & 7,850 & 7,850 & 7,850 \\
\hline
\end{tabular}

20@200, is used for both the inner and outer wall surfaces of the wall. There are 64 pre-stressing tendons in the vertical direction with a cross-section of $2400 \mathrm{~mm}^{2}$ and are pre-stressed to 3.348 $\mathrm{MN}$; for the horizontal tendons the corresponding figures are 42, $2100 \mathrm{~mm}^{2}$, and $2.929 \mathrm{MN}$. Standard elasto-plastic descriptions were used for the steel of both the reinforcing bars and the prestressing tendons.

\section{Postulated accidents and requirements}

In Europe the design of LNG tanks is governed by the standard EN 14620 [1]. The structure must satisfy a number of requirements in respect of the service limit state (SLS) and the ultimate limit state (ULS). Apart from the usual gravity, pre-stressing and operating loads, stringent criteria must be satisfied in respect of test loads (the hydraulic test, in which the tank is filled with water to reach pressures 25\% above the operating LNG pressures) and, particularly, accidental loads.

Seismic demands tend to be among the governing accidental loads in these tanks, but they are very secondary at Pori because of its exceptionally quiet seismic environment. The load cases discussed 
here are the major leak (whereupon the LNG is assumed to leak into the annular space between the two tanks), and an external fire (in which the tank is subjected to a history of radiating fluxes from a postulated external fire). Other events such as missile impact, overpressures from deflagration of a hydrocarbon cloud, etc., are studied but cannot be discussed within the limits of this paper.

In the major leak accident, when LNG is assumed to leak into the annular space, four situations are considered, corresponding to different elevations reached by the liquid; all major leaks are assumed to last sufficiently for steady state thermal conditions to develop. In the external fire the heat flux received by the tank evolves with time: during the first hour a heat flux of $42 \mathrm{~kW} / \mathrm{m}^{2}$ is applied on the wall, which reduces to $32 \mathrm{~kW} / \mathrm{m}^{2}$ for the next 5 hours.

The specific requirements include limitations on the width of the cracks developed in the concrete (0.3 $\mathrm{mm})$, a minimum residual compressed zone (RCZ) in the concrete $(90 \mathrm{~mm})$, a minimum value of the compressive force maintained by the concrete in the wall $(400 \mathrm{kN} / \mathrm{m})$, an upper limit on the plastified wall thickness $(50 \mathrm{~mm})$ and a minimum thickness of the elastic zone $(100 \mathrm{~mm})$; also, neither the reinforcing bars nor the pre-stressing tendons are allowed to yield.

\section{Analysis of major leaks}

As mentioned earlier, in a major leak the liquid LNG is assumed to leak into the annular space between the two tanks and to impose its temperatures on all wetted surfaces. The four liquid levels considered are 7.0, 10.0, 15.0, and $22.8 \mathrm{~m}$. Given the weak coupling of the thermal and mechanical problems, a thermal analysis was conducted first for each leak configuration, followed by a mechanical analysis that incorporates the thermal results as input. All calculations, for both the major leak and the external fire, were performed with Abaqus [3].

\subsection{Thermal analyses}

Thermal analyses are needed to establish both the initial conditions before the accident and the steady state temperatures for the different liquid levels. The results are imported for conducting the mechanical analyses. Five steady-state temperature distributions were calculated, corresponding to:

a) Normal operation. Temperatures in normal operation are obtained for a normal ambient temperature of $5.0^{\circ} \mathrm{C}$. The air temperature is imposed on the outer surface of the wall, the top surface of the dome, and the lower surface of the bottom slab. All surfaces in contact with the liquid are assumed to be at $-168^{\circ} \mathrm{C}$, which is the LNG design temperature.

b) Major leak. Four temperature distributions were also calculated for the four major leak hypotheses, in which a temperature of $-168^{\circ} \mathrm{C}$ is imposed on surfaces wetted by the LNG. The temperature of the outer surface is $5^{\circ} \mathrm{C}$, which is the normal ambient temperature.

The heating system is also introduced: $20.66 \mathrm{~W} / \mathrm{m}^{2}$ in the central region of the slab and a circumferential heating of $31.44 \mathrm{~W} / \mathrm{m}^{2}$ below the foamglass insulation, both active $50 \%$ of the time.

Of special interest is the case of the full major leak, in which the liquid reaches a level of $22.8 \mathrm{~m}$. The analysis indicates that cryogenic reinforcement, needed for temperatures below $-20^{\circ} \mathrm{C}$, must be used in the inner face of the tank wall at all elevations between $4.3 \mathrm{~m}$ and $27.7 \mathrm{~m}$. Also, relatively sharp vertical thermal gradients occur around the top of the TCP and in the region near the free surface of the liquid, with important effects on the local concrete stresses.

\subsection{Mechanical analyses}

The initial stress state of the structure correspond to normal operating conditions. The mechanical analyses then consist of three sequential steps, in which loads are applied as described below:

a) Pre-stressing loads. The tendon loads are kept constant in the course of this first step. The analysis determines the stable configuration on which additional loads will be applied.

b) Vapour pressure, liquid pressure and gravity. These include a vapour pressure of $40 \mathrm{kPa}$, the hydrostatic pressure corresponding to each liquid level, and gravity loads.

c) Thermal loads. The temperatures arising from the major leak accident are now introduced, which generates most of the cracking and redistribution of stresses. 
As an example, for the case of the full major leak with the liquid reaching a level of $22.8 \mathrm{~m}$, Figs. 3 and 4 present the vertical and hoop stresses in the regions of the main transitions. For lack of space, the stresses at the connection between the wall and the dome are not shown here. All stresses remain below $40 \mathrm{MPa}$.
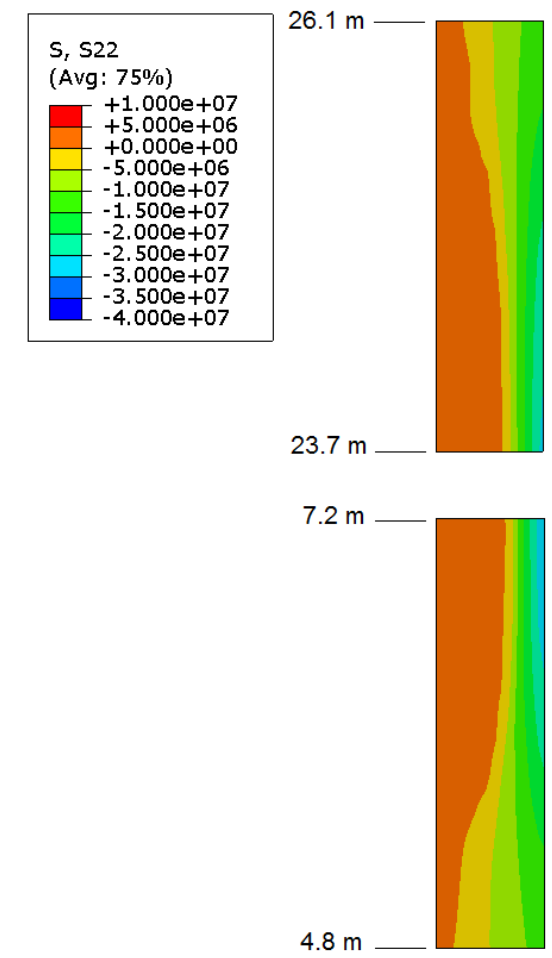

Fig. 3: Vertical stressess near the top of the TCP and the free surface
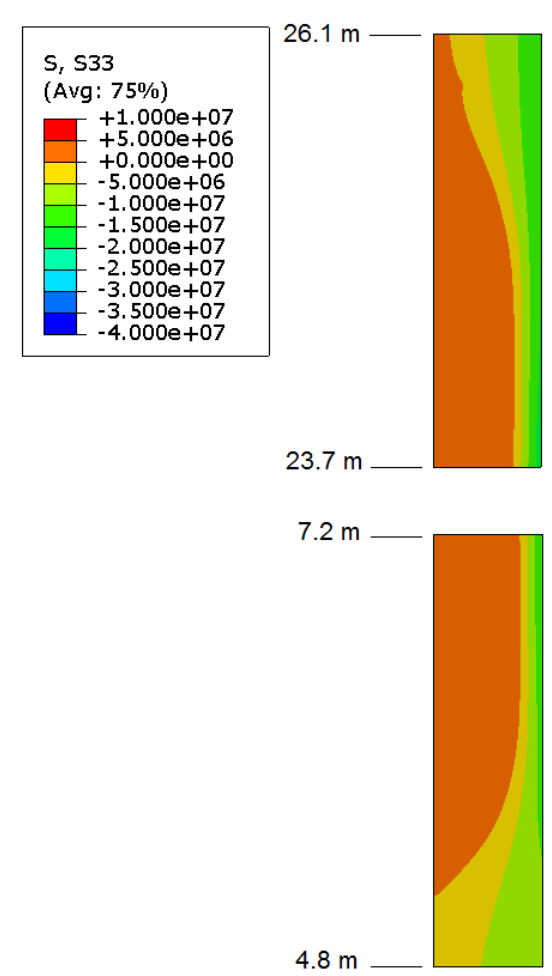

Fig. 4: Hoop stressess near the top of the TCP and the free surface

Figs. 5 and 6 show the thickness of the RCZ for the vertical and hoop stresses, respectively, for the four liquid levels; as required, they exceed $90 \mathrm{~mm}$. To guarantee the containment function of the outer tank, the compressive force per unit length of the wall must exceed $400 \mathrm{kN} / \mathrm{m}$. Alyhough not shown here, both the vertical and hoop forces satisfy the requirement for all four liquid levels.

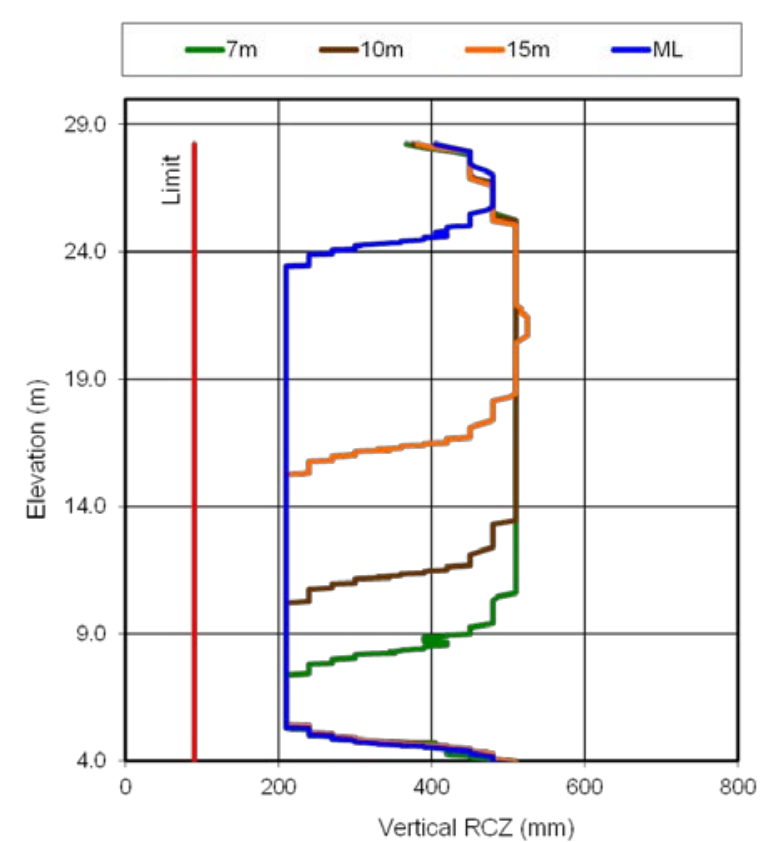

Fig. 5: Vertical residual compressed zone for various leak levels

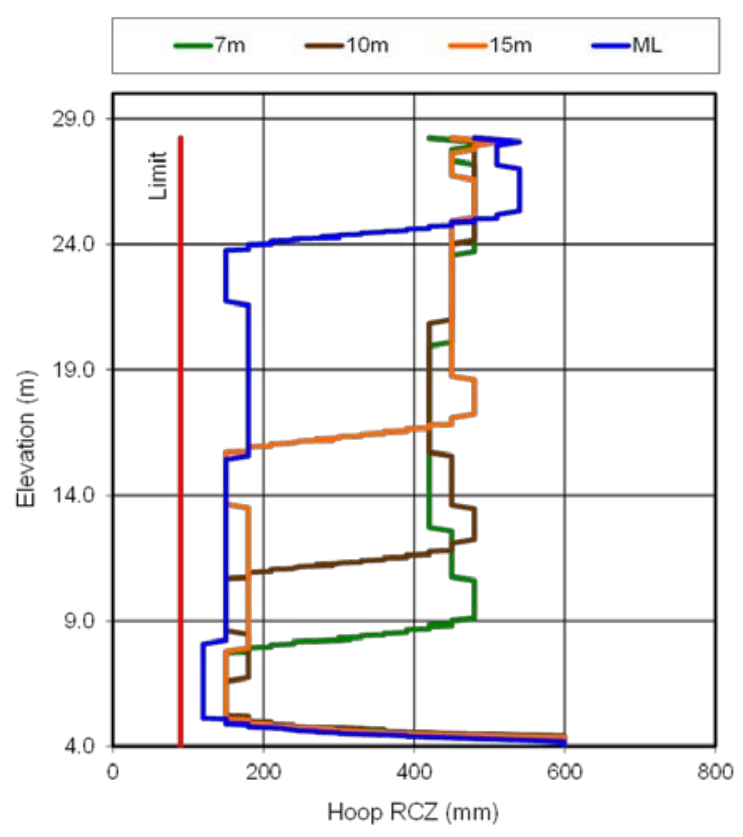

Fig. 6: Horizontal residual compressed zone for various leak levels 
The stresses in the reinforcement are also limited to $460 \mathrm{MPa}$; Figs. 7 and 8 present those stresses, together with the allowable limit. For the pre-stressing tendons, the stresses should not exceed 1770 MPa; as shown in Figs. 9 and 10, these requirements are again fulfilled.

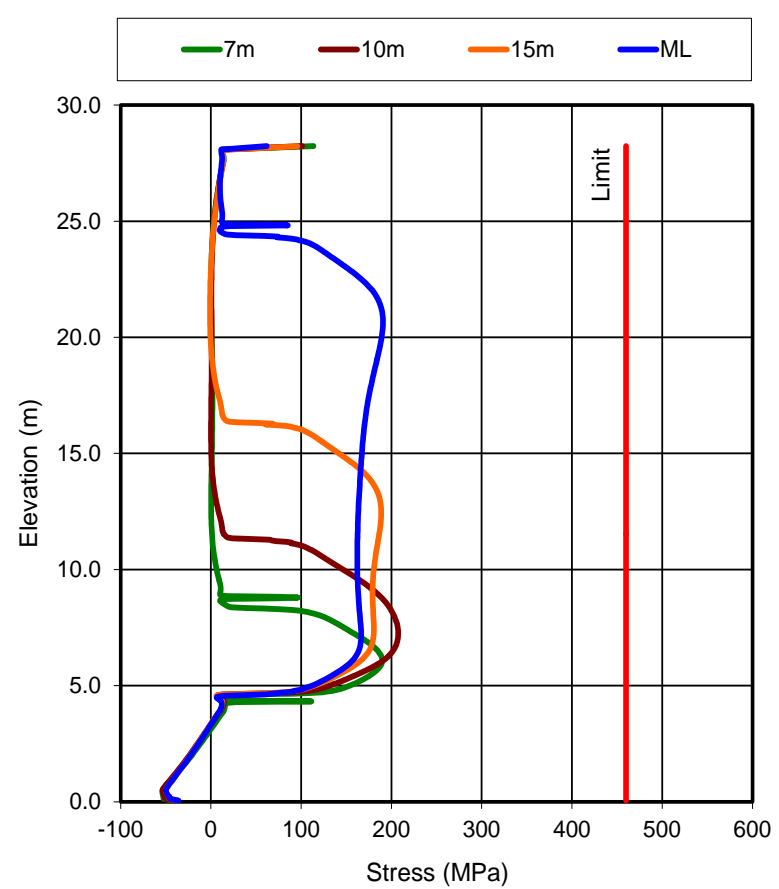

Fig. 7: Stresses in vertical reinforcement

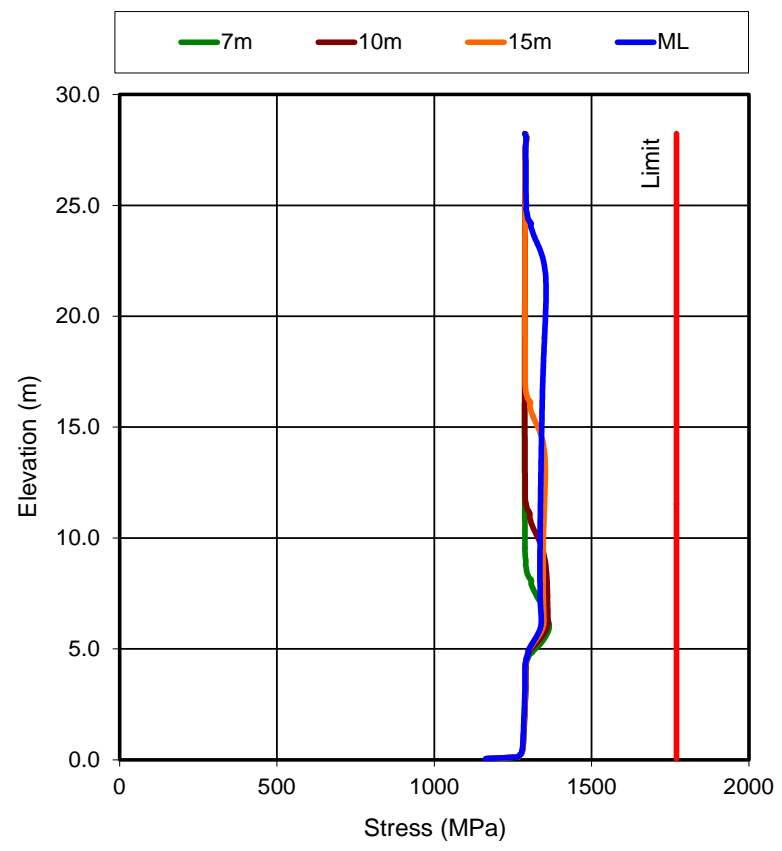

Fig. 9: Stresses in vertical tendons

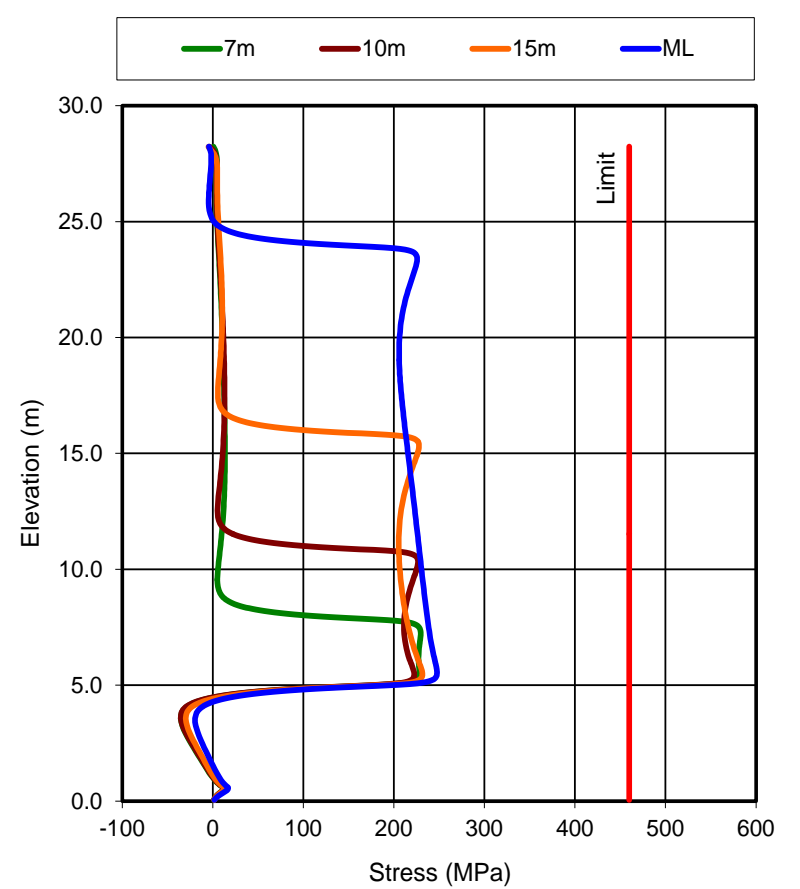

Fig. 8: Stresses in horizontal reinforcement

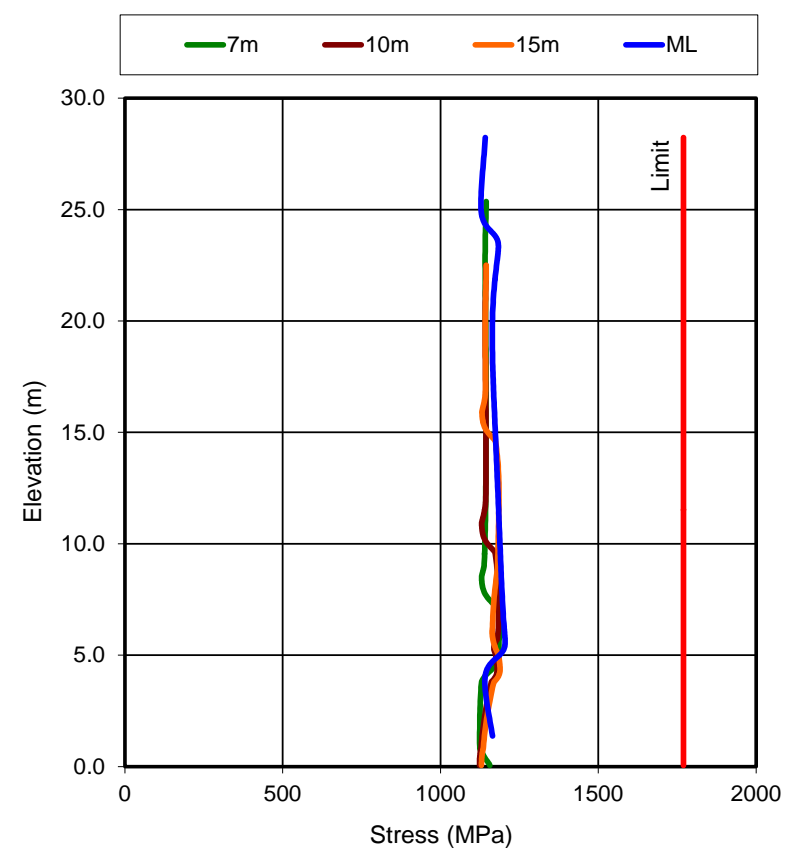

Fig. 10: Stresses in horizontal tendons

The crack widths, calculated from the reinforcement stresses for the four leak cases, are plotted together with the allowable limits in Figs. 11 and 12. Limiting the width to $0.3 \mathrm{~mm}$ around the TCP anchor intends to prevent leakage paths in that area.

The shear demands and capacities were evaluated along the wall to ensure that the reinforcement provided is adequate. The mechanical (total minus thermal) strains in the concrete were also com- 
puted to verify that they remain below $0.23 \%$, especially in the outer face of the wall, which experiences greater compression. Table 2 summarises the main verifications for elevations above $4 \mathrm{~m}$.

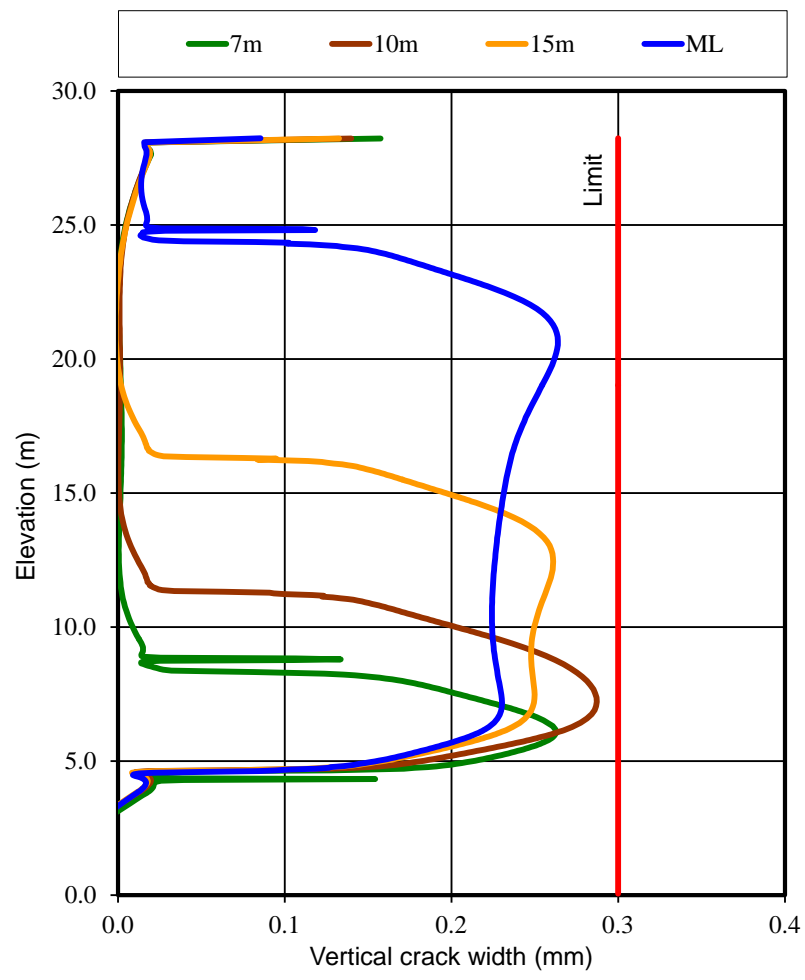

Fig. 11: Vertical crack width

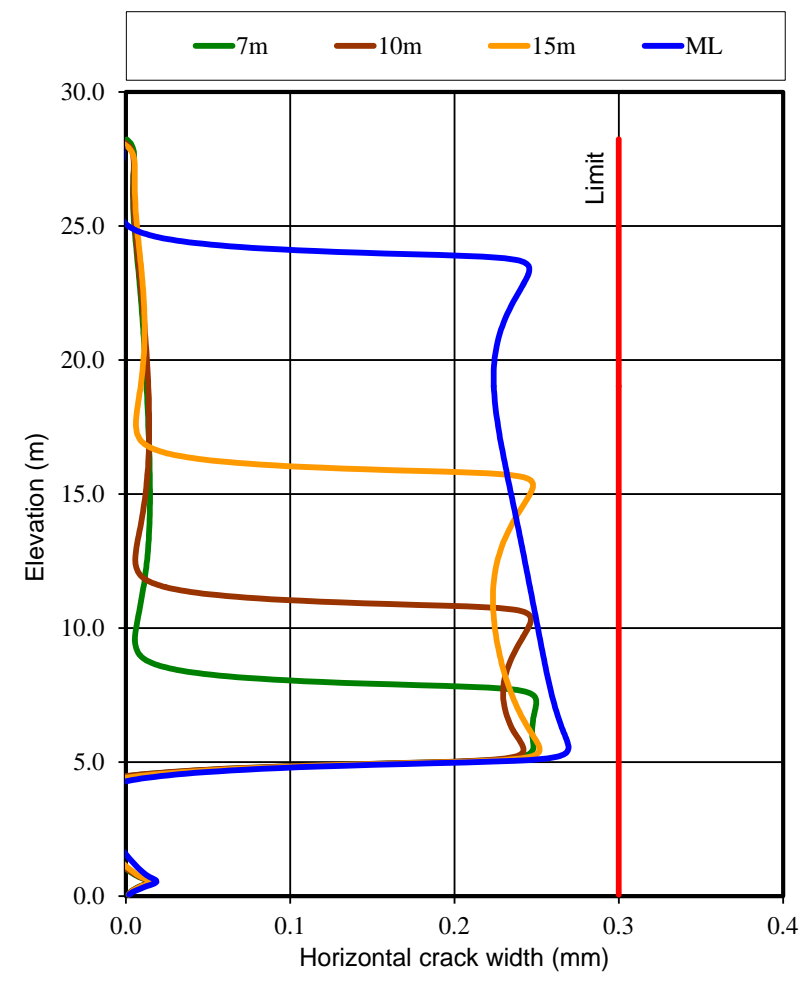

Fig. 12: Horizontal crack width

Table 2: Verifications above elevation $4 \mathrm{~m}$

\begin{tabular}{llll}
\hline Requirement & Horizontal & Vertical & Limit \\
\hline Concrete compressive stress $(\mathrm{MPa})$ & 19.9 & 28.9 & $<40$ \\
Rebar stress $(\mathrm{MPa})$ & 247.7 & 207.3 & $<460$ \\
Pre-stressing tendon stress $(\mathrm{MPa})$ & 1288 & 1365 & $<1770$ \\
Compressed zone, $R C Z(\mathrm{~mm})$ & 120 & 210 & $>90$ \\
Force per unit length, $N_{R C Z}(\mathrm{kN} / \mathrm{m})$ & 500 & 2705 & $>400$ \\
Average compression, $\sigma_{R C Z}(\mathrm{MPa})$ & 4.2 & - & $>1$ \\
Concrete mechanical strain $(\%)$ & 0.05 & 0.10 & $<0.23$ \\
Crack width around TCP $(\mathrm{mm})$ & 0.27 & 0.24 & $<0.30$ \\
\hline
\end{tabular}

\section{Analysis of external fire}

As mentioned, the heat fluxes specified evolve with time: during the first hour a heat flux of 42 $\mathrm{kW} / \mathrm{m}^{2}$ is applied on the outer tank wall, which reduces to $32 \mathrm{~kW} / \mathrm{m}^{2}$ for the next five hours. As its surface temperature increases, the outer wall radiates heat, characterised with an emissivity coefficient of 0.63 [2]. Finally, the inner surface of the insulation layer is kept at $-168^{\circ} \mathrm{C}$. As for the major leaks, the thermal problem was solved first, followed by the structural analysis.

\subsection{Thermal problem}

The thermal problem was addressed assuming axial symmetry and an infinite wall. The mesh represented the resilient blanket, the perlite, and the concrete. Wall temperatures evolve due to the heat flux imposed by the fire and that radiated by the wall.

Fig. 13 presents the temperatures in one hour intervals. The maximum temperature in the wall is $675^{\circ} \mathrm{C}$, at which the heat radiated by the wall balances the incoming heat flux from the fire. Temperatures in the horizontal and vertical tendons remain below $185^{\circ} \mathrm{C}$ and $54^{\circ} \mathrm{C}$, respectively.

The consequences of the external fire are fairly independent of the initial temperatures outside the 
tank. Also, because of the thermal inertia of the wall, the fire induces noticeable temperature changes only in the outer $20-30 \mathrm{~cm}$ of the wall.

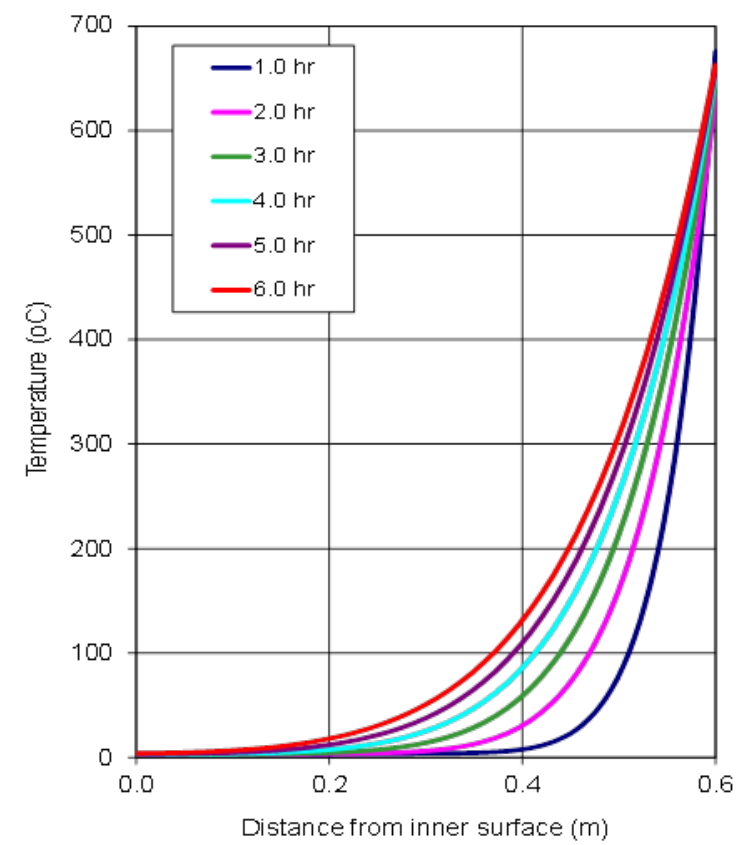

Fig. 13: Temperatures in $1 \mathrm{hr}$ intervals

\subsection{Mechanical problem}

The model used includes the vertical and horizontal tendons, as well as the reinforcing bars in the outer and inner faces of the wall. The concrete was represented with the same non-linear model of the previous section, except that its properties deteriorate with temperature. Since pre-stressing levels are not uniform in the wall, four sections were monitored, at $1.5,5.7,8.1$, and $24.2 \mathrm{~m}$.

The vertical and hoop stresses across the thickness of the wall are shown in Fig. 14 for one of the monitored sections; the compressed thickness always exceeds 100 $\mathrm{mm}$. The vertical and hoop strains appear in Fig. 15; none of the concrete regions suffer plastic deformations. Table 3 summarises the compliance with the requirements for the section with the more severe demands.

Table 3: Stresses developed in the different steel elements for section $D$

\begin{tabular}{|c|c|c|c|}
\hline Structural elements & Stress (MPa) & Temperature $\left({ }^{\circ} \mathrm{C}\right)$ & Limit (MPa) \\
\hline Vertical cryogenic rebars & 211 & 5 & 460 \\
\hline Hoop cryogenic rebars & 417 & 4 & 460 \\
\hline Vertical prestressing tendons & 1421 & 54 & 1770 \\
\hline Hoop prestressing tendons & 1153 & 185 & 1770 \\
\hline Hoop normal rebars & -261 & 486 & 500 \\
\hline Vertical normal rebars & -307 & 444 & 500 \\
\hline
\end{tabular}

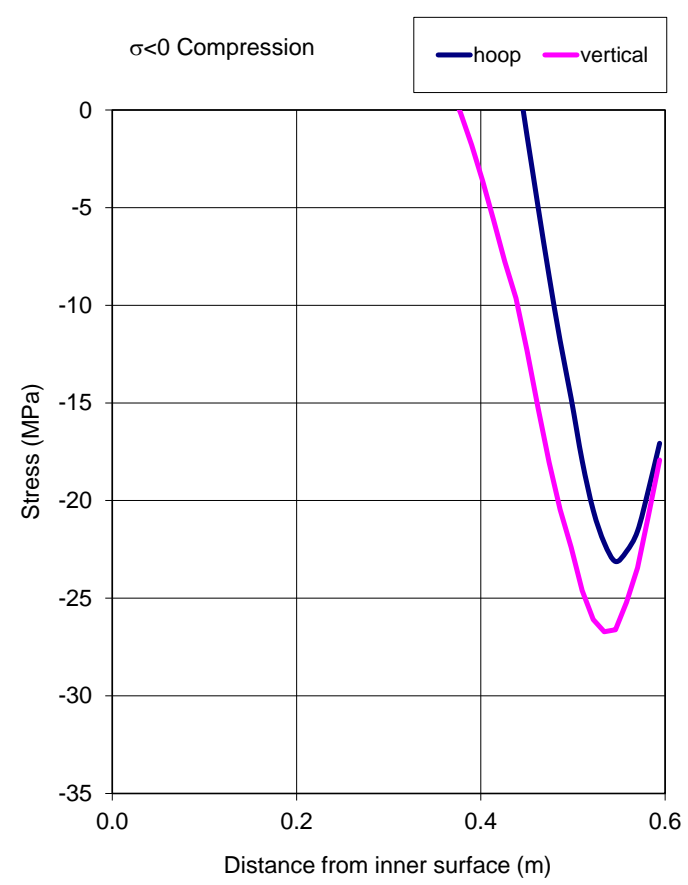

Fig. 15: Strain distributions in concrete

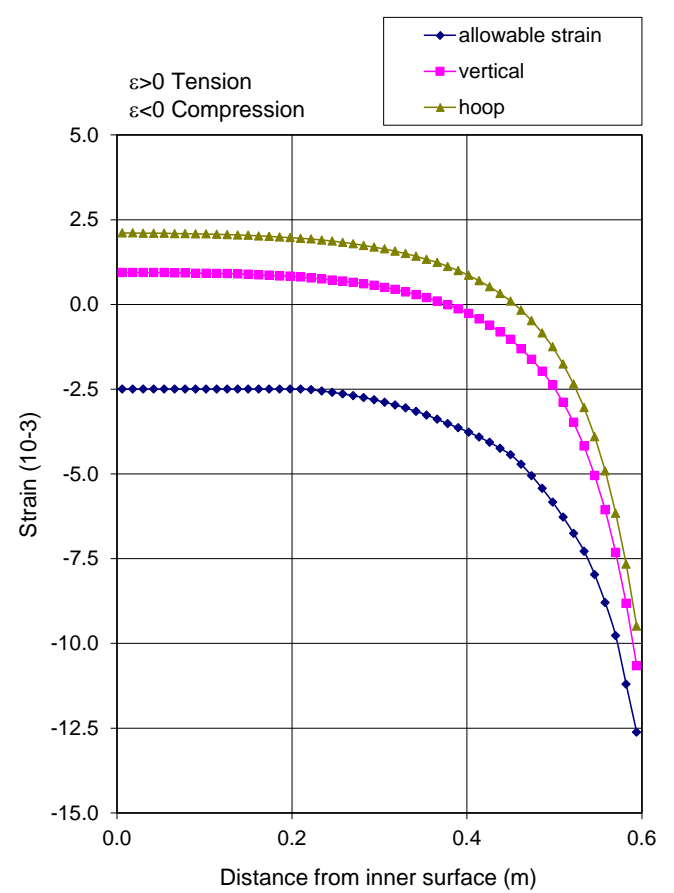

Fig. 16: Stress distributions in concrete 


\section{Conclusions}

The paper described the thermal-mechanical calculations conducted to verify that the design of the Pori tank satisfies the design requirements in respect of two postulated events: various levels of major leaks and an external fire. The calculations were carried out with the finite element code Abaqus, using temperature dependent properties for all materials, a damage plasticity model for mass concrete, and elasto-plastic formulations for the reinforcing bars and pre-stressing tendons.

As a result of the work conducted, the following conclusions can be proposed:

a) As a general conclusion, it can be stated that all of the design requirements are satisfied under both the major leak conditions and the external fire scenario.

b) The basic verifications included the thickness of the residual compressed zone (RCZ), the compressive forces per unit length of wall, the stress levels in reinforcing bars and prestressing tendons, the crack widths developed, the shear demands on the wall section, and the compressive mechanical strains.

c) Cryogenic reinforcement is required in the inner face of the wall at elevations between 4.3 and $27.7 \mathrm{~m}$, as their temperatures go below $-20^{\circ} \mathrm{C}$ during the major leak.

\section{References}

[1] CEN - European Committee for Standardization (2006) "EN 14620. Design and Manufacture of Site Built, Vertical, Cylindrical, Flat-Bottomed Steel Tanks for the Storage of Refrigerated, Liquefied Gases with Operating Temperatures between $0^{\circ} \mathrm{C}$ and $-165^{\circ} \mathrm{C}$ ”, 29 December.

[2] Faires, V.M. (1974) “Thermodynamics”, $4^{\text {th }}$ edition, The Macmillan Company, New York.

[3] SIMULIA (2013) “Abaqus Analysis User’s Guide”, Version 6.13, Providence, Rhode Island. 